\title{
Education, Research, and Training Aspects of the Sustainable Futures NSF IGERT Project
}

\author{
K. R. Haapala ${ }^{1}$, M. J. Hutchins ${ }^{1}$, J. L. Rivera ${ }^{1}$, V. Kumar ${ }^{1}$, A. R. Clarke ${ }^{1}$, \\ T. D. Eatmon ${ }^{5}$, R. A. Harris ${ }^{6}$, M. H. Durfee ${ }^{2}$, J. R. Mihelcic ${ }^{3}$, \\ D. R. Shonnard ${ }^{4}$, and J. W. Sutherland ${ }^{1}$ \\ ${ }^{1}$ Dept. of Mechanical Engr.-Engr. Mechanics, ${ }^{2}$ Dept. of Social Sciences, \\ ${ }^{3}$ Dept. of Civil and Environmental Engineering, ${ }^{4}$ Dept. of Chemical Engineering \\ Sustainable Futures Institute, Michigan Technological University, Houghton, MI \\ ${ }^{5}$ Nelson Mandela School of Public Policy and Urban Affairs, \\ Southern University and A\&M College, Baton Rouge, LA \\ ${ }^{6}$ Louisiana State University, Health Sciences Center, \\ School of Public Health, New Orleans, LA
}

\section{Introduction}

Technological innovations and industrial activities provide positive benefits to society and the economy, but can also result in negative societal and environmental impacts. Social reformers of the early industrial revolution, notably economist Thomas Malthus (1766-1834), warned of the need to consider societal impacts of new technologies. Early environmental activists including marine biologist Rachel Carson (1907-1964) cautioned industry and society that actions were adversely impacting the environment. In the 1987 report of the Brundtland Commission, titled Our Common Future, the term "sustainable development" was defined as "development that meets the needs of the present without compromising the ability of future generations to meet their own needs" (WCED, 1987). Today, industry and governmental leaders recognize the complexity of interactions among society, the economy, and the environment.

It is the mission of universities to prepare students to meet the needs of an increasingly complex society, which is demanding governments, corporations, and other organizations to act in a sustainable manner. It is envisioned that sustainability can be achieved only through informed decisions, or a metadisciplinary understanding of the issues relevant to a problem (Mihelcic et al., 2003). However, educators are struggling to incorporate sustainability into pedagogical activities, including those at the graduate level. An international survey concluded engineering students are familiar with environmental issues, but that a knowledge gap exists for legislation, policy, and standards (Azapagic, Perdan, \& Shallcross, 2005). Glavič (2006) reported that sustainability is often a topic covered in other courses, but not a stand-alone subject, worldwide.

Part of the struggle in educating engineers in sustainability is due to the lack of an operating definition that has widespread acceptance and offers useful strategies for research and for policy. Discussions of sustainability within and between the disciplines often highlight fundamental differences in attitudes towards societal issues, environmental concerns, and industrial activities. Rarely do the discussions promote convergence on approaches or key concepts. To harmonize 
the views and attitudes of disparate fields across campus, establish a common working language, and nurture the development of science base in support of sustainability, faculty, staff, and students at Michigan Technological University (MTU) formed the Sustainable Futures Institute (SFI) in 2003. SFI education, research, and outreach activities consider both the policy and technology aspects of sustainability.

Sutherland et al. (2003) reported on the development of the MTU sustainability curriculum that led to establishing the SFI. In the late 1980s and early 1990s, coursework in traditional disciplines (e.g., Chemical Engineering, Mechanical Engineering, and the Social Sciences) began to reflect the growing importance of the environment. An Environmental Policy graduate program was established that complemented the existing Environmental Engineering program. Efforts from across campus led to the Engineering for the Environment and, later, Environmentally Responsible Design and Manufacturing courses to address interdisciplinary environmental issues. Involved faculty began to serve on graduate committees outside of their disciplines; students began to participate in courses external to their disciplines. In January 2003, MTU faculty and staff participated in an Educating for the Environment Workshop, a day-long event that took stock of education-related environmental activities. Several participants were motivated to develop the Graduate Certificate in Sustainability, the first Graduate Certificate at MTU. The workshop also facilitated the collaboration of Engineering and Social Science faculty for the pilot Graduate Seminar in Sustainability that Spring. The seminar attracted a campuswide audience and has evolved into the Graduate Sustainability Research Colloquium. This and on-going discussions led to a new paradigm in education and research, termed the Sustainable Futures Model, to explain how the traditional disciplines contribute to sustainability (Fig. 1).

\section{Economic/Industrial Sustainability}

Productivity

Profit \& employment

Clean manufacturing

Design for environment

Product take-back

Life cycle engineering

Eco-efficient manufacturing

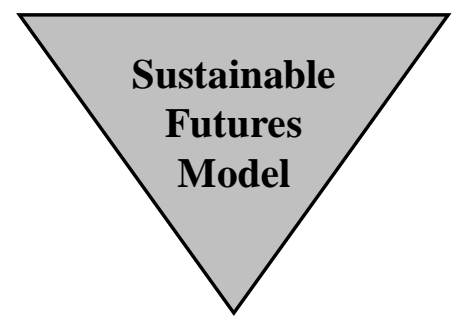

Societal Sustainability
Environmental Sustainability

Geographic information systems

Fate \& transport mechanisms

Sustainability metrics

Impact modeling

Risk assessment

Natural resources

Human \& ecosystem health

$\begin{array}{lr}\text { Informed citizenry } & \text { Risk communication } \\ \text { Stakeholder participation } & \text { Public policy } \\ \text { Social justice } & \text { Knowledge diffusion } \\ \text { Equity } & \text { Land use planning }\end{array}$

Figure 1. The Sustainable Futures Model (from Mihelcic \& Hokanson, 2005)

In spite of the progress, coverage of the economic and societal aspects of sustainability was lacking in doctoral engineering programs at MTU. Thus, it was natural to seek out a partnering doctoral program strong in these aspects to secure a National Science Foundation Integrative Graduate Education and Research Traineeship (NSF-IGERT) award. The NSF-IGERT program was established to support the education of U.S. doctoral scientists, engineers, and educators. NSF-IGERT aims to change the culture of graduate education to facilitate collaborative research 
and "to contribute to the development of a diverse, globally-engaged science and engineering workforce" with Trainees acting as creative agents for change (NSF, 2002).

As MTU was infusing sustainability concepts in its engineering doctoral programs, Southern University and A\&M College in Baton Rouge (SUBR), Louisiana, was nurturing the growth of its doctoral program in Public Policy. This program, established in 1996, is housed in the Nelson Mandela School of Public Policy and Urban Affairs and has concentrations in environment, health, public finance, and sustainability policy. SUBR and MTU administrations have supported collaborative education and research activities between the institutions for more than a decade; the NSF-IGERT offered a perfect opportunity to take advantage of the complementary strengths. In the Fall of 2002, a group of engineering and policy researchers from MTU approached engineering and policy faculty at SUBR concerning the NSF-IGERT. Two years later, the first cohort of IGERT engineering and policy graduate students began its studies at MTU and SUBR.

In this paper, the key components of the Sustainable Futures (SF) IGERT project are reported, including research foci, educational offerings, and institution issues. Education and training features of the SF IGERT include sustainability courses, colloquia, international experiences, internships, and a semester-long exchange to the university partner. Benefits derived from the SF IGERT project and challenges faced during its development and delivery are reported.

\section{Sustainable Futures IGERT Project}

The SF IGERT project has brought together IGERT scholars (NSF-funded Trainees and university/industry-funded IGERT Associates) from Civil \& Environmental Engineering, Chemical Engineering, Geological Engineering, Mechanical Engineering, and Environmental Policy at MTU and Public Policy at SUBR. IGERT scholars interact with students, faculty, and staff from other departments in the SFI community, e.g., Forestry, Biology, and the Humanities, and take part in programmatic educational, research, and training features as discussed below.

\subsection{Educational Aspects}

SF IGERT scholars develop expertise in their disciplines while expanding their knowledge in others, to develop a metadisciplinary understanding of sustainability and to become agents of change in their careers. Two new interdisciplinary courses (3-credits) were developed through the SF IGERT project by MTU and SUBR faculty. Sustainable Futures 1 focuses on the tools and methods needed for policy evaluation and sustainability assessment (e.g., life cycle analysis) and concentrates on issues relevant to industrialized countries. Sustainable Futures 2 examines policy implications of sustainability, especially in the developing world. Completion of these courses is a requirement of the Graduate Certificate in Sustainability. ${ }^{1}$ The certificate also requires students to complete at least one course associated with each of the three pillars of sustainability, i.e., environmental, social, and industrial/technological systems.

Another important educational feature of the project engages IGERT Trainees from MTU engineering programs and the SUBR public policy program in a semester-long exchange at the partner institution. MTU hosts students in the fall; SUBR hosts students in the spring. Students broaden their knowledge of sustainability from another disciplinary perspective, while

\footnotetext{
${ }^{1}$ For students enrolled in the Master's International Program that allows students to combine graduate education/ research with service in the U.S. Peace Corps, another 3-credit course can be substituted for Sustainable Futures 2. 
developing an appreciation for regions with different climates, demographics, and histories. Colocation allows students to share academic experiences by attending classes together and collaborating on projects. The experience seeks to cultivate a community among the scholars and to establish lifelong professional and personal relationships. To integrate the knowledge gained through these experiences into student research, engineering dissertations are required to discuss the policy and sustainability implications of the experimental and/or theoretical research. Policy dissertations are required to discuss the technological challenges and opportunities. The advisory committee for SF IGERT Trainees includes both engineering and policy faculty members, to ensure that technological and policy implications of their graduate work are properly addressed.

\subsection{Research Aspects}

The educational aspects of the SF IGERT project provide a foundation for research. Individual research projects are aimed at advancing the science of sustainability as a metadisciplinary endeavor. Interuniversity, interdepartmental, and interdisciplinary research projects have been successfully accomplished or are underway. The benefits of these collaborations are seen in the quality and creativity of the work spawned by the SF IGERT, as discussed below.

\section{Interuniversity Collaboration}

SF IGERT scholars and faculty from MTU and SUBR partnered with Partido State University (Philippines) to design sustainable and appropriate building materials for developing countries. The feasibility of reducing cement use by adding natural pozzolans (e.g., diatomaceous earth, volcanic ash, and rice husk ash) to the binder in concrete was studied. Natural pozzolans reduce building costs and environmental pollution. This interuniversity collaboration won a prestigious Mondialogo Engineering Award (2005) and a U.S. EPA People, Prosperity, and Planet (P3) Phase 1 award, and led to publications by Harris, Eatmon, \& Seifert (2005), Mihelcic, Eatmon, Muga, \& Harris (2007), and Huntzinger \& Eatmon (2007).

Another collaborative effort spawned by the SF IGERT is the NSF Research Experience for Undergraduates (REU) grant, which allows 16 undergraduates from around the U.S. to pursue summer research in sustainability at MTU or SUBR. SF IGERT scholars bridge the gap between undergraduate students and faculty mentors and model behavior for success in graduate school. Also, students from both institutions have collaborated on research projects as a result of the SF IGERT. A public policy IGERT Trainee (SUBR) and environmental engineering IGERT Trainee (MTU) collaborated on a paper on coastal wetland policies for Louisiana and Senegal. They presented their work in Senegal (Seifert \& Fuchs, 2005) and at their home institutions. An interuniversity publication by Harris, Haciogullari, Shams, \& Abood (2007), Lines in the Sand, maps the natural (oil, water) and social (ethnic, religious groups) resources in Iraq, and identifies conditions for unification or partition of the country into three states to resolve their conflict.

\section{Interdepartmental Collaboration}

In addition to facilitating collaboration between the universities, the SF IGERT project has helped bridge departmental divides and creative and complex problem-solving efforts. The MTU Wood-to-Wheels Graduate Enterprise spans Biology, Business, Chemistry, Chemical Engineering, Civil \& Environmental Engineering, Forestry, Mechanical Engineering, and Social Sciences, and has attracted international attention. Involved SF IGERT scholars and faculty are 
studying technologies across the value chain to improve forest biomass productivity, conversion to biofuels, engine and vehicular systems, and knowledge of societal attitudes and policies.

The MTU International Sustainable Development Engineering Research Experiences Program involves SF IGERT scholars and faculty from across campus in the pursuit of appropriate technologies for developing world communities. In its first year, it is a collaborative effort of students from Civil \& Environmental Engineering, Mechanical Engineering, and Electrical Engineering and the Social Sciences. Currently, the program seeks to expose students to new languages and cultures while pushing them to evaluate and design sustainable wastewater treatment systems in rural Bolivia. Other international efforts with a focus on sustainability that are related to the SF IGERT project are described elsewhere (Fuchs \& Mihelcic, 2006; Mihelcic, Phillips, \& Watkins, 2006; Paterson, Phillips, Watkins \& Mihelcic, 2006; Hokanson et al., 2007a). A team of business and engineering graduate students, for example, investigated barriers to drinking water technology implementation in the developing world (Hokanson et al., 2007b).

\section{Interdisciplinary Thinking}

SF IGERT-related research spans multiple disciplines and projects have included knowledge and tools from many academic perspectives. Corporate social responsibility was explored from a business, social science, environment, and engineering perspective by a mechanical engineering IGERT Trainee. A public policy IGERT Trainee is investigating the industrial environmental risks in the face of natural disasters. A mechanical engineering IGERT Trainee is incorporating environmental engineering pollution evaluation tools into supply chain performance cost measures. Through collaboration among departments, disciplines, and universities, the SF IGERT project is striving to answer difficult and complex questions about sustainability, which requires novel sets of knowledge and skills. The global social, environmental, economic, and technical challenges necessitate exactly this type of innovative, multi-disciplinary research.

\subsection{Training Aspects}

Beyond the novel research and educational programs, the SF IGERT is designed to provide training for students to address the complex needs of a sustainable society. Training expectations are designed to be flexible to meet individual needs of students as well as institutional requirements. The NSF places importance on professional development and so the SF IGERT facilitates programming not typical of other doctoral programs. Training aspects, including internships, international experiences, and professional development, allow personal growth and development that emphasizes communication, teamwork, leadership skills, and multiculturalism.

\section{Internships}

Internships provide practical experience in the private and public sectors. These sectors often have dissimilar interests and concerns, allowing students to approach sustainability issues from perspectives very different from those of academia. Upon the completion of an internship, students share their experience with other SF IGERT scholars. Involvement in projects at the host organizations serves to develop professional skills and contributes diverse insights to sustainability research.

In the private sector as interns at Caterpillar, an environmental engineering IGERT Trainee participated in corporate policy development and a mechanical engineering IGERT Trainee 
examined environmental effects of new materials. In the public sector, a chemical engineering IGERT Trainee investigated lower-cost materials to improve fuel cell performance at Argonne National Laboratory and a public policy IGERT Trainee will be a visiting scholar at Allegheny College for the 2007-08 academic year. Such internships have helped to cultivate a wider range of skills than traditionally acquired by doctoral students.

\section{International Experiences}

International experiences develop personal and professional skills not possible with a domestic internship by allowing students to participate in technical meetings, learn state-of-the-art methods and software, and implement sustainable solutions while abroad. SF IGERT scholars are able to experience other languages, cultures, and customs and to share these experiences. International experiences require a significant amount of time outside of the U.S. and can include an international internship.

SF IGERT Trainees have worked on projects to implement sustainable technologies in developing countries such as Brazil, Bolivia, and the Philippines. One student has applied the Sustainable Futures Model to problems of the developing world (Fuchs and Mihelcic, 2006). Trainees have also participated in international academic research sponsored by the University of Oulu in Oulu, Finland and the Swiss Federal Institute of Technology in Zurich, Switzerland. Scholars from MTU and SUBR have attended international conferences in various countries including Belgium, Brazil, Canada, Mexico, Senegal, Switzerland, and Uganda. Internships and international experiences are integral to professional development features of the SF IGERT.

\section{Professional Development}

Development of professional skills and exposure to professional development topics such as public presentation, writing, ethics, and life as a professor prepares SF IGERT scholars to excel and succeed in their chosen careers. Professional development activities have been included as a part of the IGERT Annual Summit, Professional Development Week, Graduate Research Colloquium, Brown Bag Seminar Series, and student publications and presentations.

The IGERT Annual Summit alternates between the MTU and SUBR campuses. This meeting allows SF IGERT scholars and faculty to meet, interact, and evaluate research, education, and institutional issues. Professional Development Week is sponsored by the SFI and held at MTU at the beginning of the fall semester for all graduate students conducting sustainability research, including MTU and SUBR IGERT scholars on campus; it includes workshops on conducting sustainability research, preparing publications, curriculum vitae preparation, and grant proposal writing among others. The Graduate Research Colloquium and Brown Bag Seminars offer venues for students to discuss current sustainability literature, present their research, and hear about sustainability activities on and off campus. Publishing and presenting at conferences allows students to gain experience networking and communicating with experts in their fields.

SF IGERT scholars also gain experience that will benefit future careers in teaching. They participate in organizing class sessions, selecting course topics, and discussions about course improvement. IGERT Trainees at MTU are required to enroll in ED5100, Introduction to College-level Teaching. IGERT Trainees at SUBR participate in a required teaching experience. 
These requirements ensure understanding of recent pedagogical theories and processes of student learning, instructional strategies, student motivation, and instructional technology.

\section{Benefits and Challenges}

One of the greatest benefits of the Sustainable Futures (SF) IGERT project is the level of collaboration between disciplines. Since the project started, sustainability-related papers have been published by faculty and students from different departments in such prestigious journals as Environmental Science \& Technology, the Journal of Cleaner Production, the Annals of the CIRP, and the International Journal of Engineering Education. Students have been involved in publishing interdisciplinary papers. For example, a mechanical engineering student published work focused on the environmental and economic sustainability of automobile recycling (Kumar \& Sutherland, 2007) and SF IGERT Trainees and faculty from Civil \& Environmental Engineering, Geological Engineering, and Mechanical Engineering published several papers on engineering education (Beach, Hutchins, Gierke, \& Sutherland, 2007; Troschinetz, Mihelcic, \& Bradof, 2007). Success has been seen in interdisciplinary projects and proposal efforts such as an NSF MUSES grant and the Wood-to-Wheels initiative, both on biofuels research. The interdisciplinary nature of the SF IGERT allows students, who traditionally are immersed in their own activities and collaborate only with peers in similar areas, to expand their collaborative networks and understand broader issues related to their work.

Efforts related to the SF IGERT have supported broader goals at the university level. Michigan Tech has chosen to focus on sustainability in their strategic plan, their regional accreditation, and as one of the key research areas for the university. The University board has agreed and as a consequence strategic hiring of faculty in support of sustainability will be taking place over the next decade. The administrations of MTU and SUBR have made changes to internal policies to be more flexible to innovative education and research programs, including facilitating student exchanges at the doctoral level.

SF IGERT faculty, staff, and students at MTU and SUBR have faced several challenges in the development and delivery of the SF IGERT project. Although the interdisciplinary papers, projects, and proposal exhibit healthy collaboration, one challenge has been communication among the various groups. There are areas where improved communication would be beneficial, e.g., expanding the science of sustainability through a collaborative effort to develop a common technical language and improving knowledge of ecosystem dynamics for both engineering and policy students. Departmental scope and vision can limit the involvement of faculty in such efforts, and traditional focus can present an emotional barrier to introducing a multidisciplinary research culture. The lack of a dedicated gathering location for all faculty, staff, and students involved presents a physical barrier for development of a common technical language. To overcome physical barriers between the partnering universities, distance learning through videoconferencing is used to link classes and colloquia on sustainability.

While faculty members are always willing to provide advice, the desire of the SF IGERT scholars to break down traditional barriers and investigate issues far outside traditional disciplines has posed mentoring challenges. To some degree, the faculty are building a facilitative language as they advise across the disciplines. Faculty members have begun to wonder if a different structure for teaching and research is in order, one that would further 
facilitate interdisciplinary work. New course development to support the growing number of students focused on sustainability that meets their educational needs also has been a challenge for faculty. Some faculty are ill-prepared to deliver courses that blur traditional disciplinary lines or are occupied by traditional courses. Books and other instructional material can be limited. Due to the widespread interest of students, even independent study courses have presented challenges. Despite a lack of appropriate materials, the recognized goal of satisfying the educational needs of students has led to much progress in appropriate topical coverage and instructional strategies. SF IGERT scholars have been an integral part of this success by providing constructive feedback and suggestions for improvement in the development and delivery of the new courses. Involved faculty from divergent disciplines (e.g., Social Science and Chemical Engineering) have delivered team-taught courses for undergraduate and graduate students from multiple disciplines that explore the area where these disciplines meet.

\section{Summary and Conclusions}

The education, research, and training aspects of the Sustainable Futures (SF) IGERT project have been described. The National Science Foundation-sponsored project involves doctoral engineering (chemical, civil, environmental, geological, mechanical) students from Michigan Technological University, in Houghton, MI and doctoral public policy students at Southern University and A\&M College in Baton Rouge, LA. In addition, SF IGERT Associates at the masters and doctoral level participate in SF IGERT-related activities. Project successes have motivated SF IGERT faculty, staff, and students to continue their efforts and challenges have been a source of inspiration for innovative solutions. In this way, the faculty- and student-led efforts have actually prompted institutional change.

\section{Acknowledgement}

The authors gratefully acknowledge the support from the National Science Foundation through the Sustainable Futures IGERT project (DGE 0333401), the Research Experiences in Sustainability for Undergraduates project (EEC-0453174), and the Integration of an International Research Experience in Bolivia with Sustainable Development Engineering Education project.

\section{References}

Azapagic, A., Perdan, P., \& Shallcross, D. 2005. How much do engineering students know about sustainable development? The findings of an international survey and possible implications for the engineering curriculum. European Journal of Engineering Education, 30(1), 1-19.

Beach, D.N., Hutchins, M.J., Gierke, J.S., \& Sutherland, J.W. 2007. Evolving Undergraduate Engineering Education for the 21st Century, Part 1: Enabling Sustainable Thinking. International Journal of Engineering Education, 23(2), 218-230.

Fuchs, V.J. \& Mihelcic, J.R. 2006. Engineering Education for International Sustainability: Curriculum Design under the Sustainable Futures Model. Proceedings of 5th Annual ASEE Global Colloquium on Engineering Education, Rio de Janeiro, Brazil, October 9-12, 2006.

Glavič, P. 2006. Sustainability Engineering Education. Clean Tech. and Env. Policy, 8(1), 24-30. 
Harris, R.A, Eatmon, T.D, \& Seifert, C.W.A. 2005. Natural Pozzolans for Sustainable Development: Mapping Poverty in the Philippines. Proceedings of the 25th Annual ESRI International User Conference, July 25-29, San Diego, CA.

Harris, R.A., Haciogullari, B., Shams, A., \& Abood S.A. 2007. Lines in the Sand: Sustainable Development in Iraq. Proc. 27th Annual ESRI Int'l User's Conf., Aug. 18-22, San Diego, CA.

Hokanson, D.R., Phillips, L.D., \& Mihelcic, J.R. 2007a. Educating Engineers in the Sustainable Futures Model with a Global Perspective: Education, Research and Diversity Initiatives. International Journal of Engineering Education, 23(2), 254-265.

Hokanson, D.R., Zhang, Q., Cowden, J.R, Troschinetz, A.M., Mihelcic, J.R., \& Johnson D.M. 2007b. Challenges to Implementing Drinking Water Technologies in Developing World Countries. Environmental Engineer, 43(1), 31-38.

Huntzinger, D. \& Eatmon, T.D. 2007. A Life Cycle Assessment of Portland Cement Manufacturing: Comparing the Traditional Process with Alternative Technologies. Journal of Cleaner Production, In Review.

Kumar, V.\& Sutherland, J.W. 2007. Infrastructure Changes Required to Achieve Higher Material Recovery Targets from End-of-Use Vehicles. Trans. of NAMRI/SME, 35, 201-208.

Mihelcic, J.R., Crittenden, J.C., Small, M.J., Shonnard, D.R., Hokanson, D.R., Zhang, Q., Chen, H., Sorby, S.A., James, V.U., Sutherland, J.W., \& Schnoor, J.L. 2003. Sustainability Science and Engineering: The Emergence of a New Metadiscipline. Env. Sci. \& Tech., 37(23), 5314-5324.

Mihelcic, J.R., Eatmon, T.D., Muga, H., \& Harris, R.A. 2007. Engineering Sustainable Construction Materials for the Developing World: Consideration of Engineering, Societal, and Economic Issues. Int'l J. of Eng. Educ., Special Issue: Educ. Students in Sus. Eng., To Appear.

Mihelcic, J.R. \& Hokanson D.R., 2005. Educational Solutions: For a more Sustainable Future. Environmental Solutions. N. L. Nemerow and F. J. Agardy, eds., Elsevier, 25-58.

Mihelcic, J.R., Phillips, L.D. \&. Watkins Jr., D.R. 2006. Integrating a Global Perspective into Education \& Research: Engineering International Sustainable Development. Environmental Engineering Science, 23(3), 426-438.

National Science Foundation (NSF). 2002. Integrative Graduate Education and Research Traineeship (IGERT) Program, Program Solicitation, NSF 02-145.

Paterson, K.G., Phillips, L.D., Watkins Jr., D.R., \& Mihelcic, J.R. 2006. International Service Engineering Across Academic Borders. ASEE Annual Conf. \& Expo. June 18-21, Chicago, IL.

Seifert, C.W.A. \& Fuchs, V. 2005. Coastal Wetlands for Sustainable Development: A Needs Assessment and Policy Adoption for the State of Louisiana and the Republic of Senegal. Proc. of 5th Int. Conf. on Public Management, Policy, and Development, June 18-22, Dakar, Senegal.

Sutherland, J.W., Kumar, V., Crittenden, J.C., Durfee, M.H., Gershenson, J.K., Gorman, H., Hokanson, D.R., Hutzler, N.J., Michalek, D.J., Mihelcic, J.R., Shonnard, D.R., Solomon, B.D., \& Sorby S. 2003. An Education Program in Support of a Sustainable Future. Proceedings of 2003 ASME IMECE, 14, 611-618. 
Troschinetz, A.M., Mihelcic, J.R., \& Bradof, K.L. 2007. Evolving Engineering Education for the 21st Century, Part 2: Developing Sustainability Indicators for a University Campus, International Journal of Engineering Education, 23(2):231-241.

World Commission on Environment and Development (WCED). 1987. Our Common Future. Oxford University Press, New York, NY.

\section{Biographical Information}

KARL R. HAAPALA is a Ph.D. Candidate/IGERT Trainee at Michigan Technological University. He received his B.S. (2001) and M.S. (2003) in Mechanical Engineering from Michigan Tech. His current research focuses on process modeling to predict environmental performance of steelmaking, sand casting, and heat treatment operations.

MARGOT J. HUTCHINS is a Ph.D. Candidate/IGERT Trainee at Michigan Technological University. She received her B.S. (2002) and M.S. (2007) in Mechanical Engineering from Michigan Tech. Her research focuses on exploring and identifying techniques that will improve decision-making with respect to the social dimension of sustainability.

JULIO L. RIVERA is a Ph.D. Candidate/IGERT Trainee at Michigan Technological University. He received his B.S. (2004) in Mechanical Engineering from the University of Puerto Rico-Mayagüez. His research focuses on product life cycle analysis and the mechanisms in air and potential health implications of nanoparticles.

VISHESH KUMAR is a Post-doctoral Associate in the Sustainable Futures Institute at Michigan Technological University. He received his B.Tech. (2000) from IIT-Kanpur and Ph.D. (2006) from Michigan Tech in Mechanical Engineering. His research interests include product end-of-life strategies, renewable energy, and life cycle analysis.

ABIGAIL R. CLARKE is a Ph.D. Candidate/IGERT Trainee at Michigan Technological University. She received her B.A. (2004) in Physics from Earlham College and M.S. (2006) in Mechanical Engineering from Michigan Tech. Her current research focuses on siting issues with remanufacturing facilities.

THOMAS D. EATMON, JR. is a Ph.D. Candidate/IGERT Trainee at Southern University. He received his B.S. (2002) in Chemical Eng. from NC State Univ. and M.Ed. (2004) from the Univ. of St. Thomas. His research concerns the adoption/implementation of international environmental agreements, as well as technology transfer.

RONALD A. HARRIS is the Program Director for Health Policy and Systems Management and an Assoc. Professor at the School of Public Health, LSU Health Sciences Center in New Orleans and past director of the SF IGERT project at Southern University. His interests are in social institutions, sustainable development, and health policy.

MARY H. DURFEE is the Assistant Provost for Academic Improvement and an Associate Professor of Political Science at Michigan Tech. She received her Ph.D. (1990) from Cornell University. Her research and teaching interests are focused on U.S. foreign policy, international environmental technology policy, and water policy.

JAMES R. MIHELCIC is a Professor in Civil \& Environmental Engineering at Michigan Technological University and past co-director of the Sustainable Futures Institute. His interests are focused on biological processes applied to natural/engineered systems, green engineering and sustainability, and engineering issues of the developing world.

DAVID R. SHONNARD is a Professor in Chemical Engineering and deputy director of the Sustainable Futures Institute (SFI) at Michigan Tech. He received his Ph.D. (1991) from the Univ. of California-Davis. His research and teaching interests focus on life-cycle assessment and bioengineering for production of bio-based fuels and products.

JOHN W. SUTHERLAND is the Henes Chair Professor of Mechanical Engineering, director of the SFI, and director of the SF IGERT project at Michigan Tech. He received his Ph.D. (1987) from the University of Illinois at Urbana-Champaign. His research and teaching interests are focused on design and manufacturing for sustainability. 